\title{
Simulation of a Shear Coaxial GO2/GH2 Rocket Injector with DES and LES Using Flamelet Models
}

\author{
Siddharth Thakur and Jeffrey Wright \\ Streamline Numerics, Inc., Gainesville, FL, 32609, U.S.A. \\ Matthias Ihme \\ University of Michigan \\ P. Kevin Tucker \\ NASA Marshall Space Flight Center
}

\section{Introduction}

$\mathrm{T}$

HE analysis and design of rocket propulsion systems largely relies on full-scale prototype development and testing. Computational simulation techniques have the potential to assist in the design process if accurate physical models are available. The objective of this study is to address this issues by assessing the predictive capability of three different modeling approaches to simulate the reactive flow field structure of a shear-coaxial rocket injector [1,2]. To this end, simulations of increasing computational fidelity will be employed, consisting of steady and unsteady Reynolds Averaged Navier-Stokes (U/RANS) calculations, and a large-eddy simulation (LES). For the prediction of the reacting flow field in the rocket injector, a flamelet-based combustion model will be employed [3, 4]. In this formulation, all chemical species, temperature, and thermo-viscous properties are represented by a reduced set of scalars, consisting of the mixture fraction and a reaction progress variable. Effects of turbulence chemistry interaction are incorporated through a presumed PDF formulation. Over recent years, numerous validation studies of rocket injector configurations have been conducted. Most notable is the comprehensive validation effort by Tucker et al. [5]. In this investigation, the GO2/GH2 single element injector configuration by Pal et al. [6] was modeled by different groups. Although this comparison provided valuable insight on wall-heat transfer predictions, it did not allow for an objective quantitative comparison, since all simulations utilized different modeling approaches, turbulence closures, combustion models, and chemical mechanisms. Furthermore, different computational grids were utilized and simulations in two-dimensional and three-dimensional computational domains were performed. The present study attempts to make a more objective comparison among URANS, DES and LES simulations.

\section{URANS and DES Solver: Loci-STREAM}

The computational tool used for URANS and DES computations is called Loci-STREAM [7]. It is a second-order accurate, pressure-based, Reynolds-averaged Navier-Stokes (RANS) code for unstructured grids, and is designed to handle all-speed flows (incompressible to supersonic). As such, the code is particularly suitable for solving multispecies flow in fixed-frame combustion devices. The flow solver is based on the SIMPLE (Semi-Implicit Method for Pressure-Linked Equations) algorithm [8]. It uses a control volume approach with a collocated arrangement for the velocity components and the scalar variables like pressure. Pressure-velocity decoupling is prevented by employing the momentum interpolation approach; this involves adding a fourth-order pressure dissipation term while estimating the mass flux at the control volume interfaces [9]. The velocity components are computed from the respective momentum equations. The velocity and the pressure fields are corrected using a pressure correction $\left(p^{\prime}\right)$ equation. The correction procedure leads to a continuity-satisfying velocity field. The whole process is repeated until the desired convergence is reached.

The programming framework for the development of Loci-STREAM is called Loci [10] and is designed to reduce the complexity of assembling large-scale finite-volume applications as well as the integration of multiple applications in a multidisciplinary environment. Unlike traditional procedural programming systems (C, FORTRAN) in which one writes code with subroutines, or object-oriented systems (C++, Java) in which objects are 
the major program components, Loci uses a rule-based framework for application design. Users of Loci write applications using a collection of "rules" and provide an implementation for each of the rules in the form of a C++ class. In addition, the user must create a database of "facts" which describe the particular knowns of the problem, such as boundary conditions. Once the rules and facts are provided, a query is made to have the system construct a solution. One of the interesting features of Loci is its ability to automatically determine the scheduling of events of the program to produce the answer to the desired query, as well as to test the consistency of the input to determine whether a solution is possible given the specified information. The other major advantage of Loci to the application developer is its automatic handling of domain decomposition and distribution of the problem to multiple processors.

\section{A. Governing Equations}

The Favre-averaged Navier-Stokes equations of mass continuity, momentum, energy and species transport are:

$$
\begin{aligned}
& \frac{\partial \bar{\rho}}{\partial t}+\frac{\partial \bar{\rho} u_{j}}{\partial x_{j}}=0 \\
& \frac{\partial \bar{\rho} u_{i}}{\partial t}+\frac{\partial \bar{\rho} u_{j} u_{i}}{\partial x_{j}}=-\frac{\partial \bar{p}}{\partial x_{i}}+\frac{\partial}{\partial x_{j}}\left(\tilde{\tau}_{i j}-\overline{\rho u_{i}^{\prime \prime} u_{j}^{\prime \prime}}\right) \\
& \tilde{\tau}_{i j}=\mu\left(\frac{\partial u_{i}}{\partial x_{j}}+\frac{\partial u_{j}}{\partial x_{i}}\right)-\frac{2}{3} \mu \frac{\partial u_{k}}{\partial x_{k}} \delta_{i j} \\
& -\overline{\rho u_{i}^{\prime \prime} u_{j}^{\prime \prime}}=\mu_{t}\left(\frac{\partial u_{i}}{\partial x_{j}}+\frac{\partial u_{j}}{\partial x_{i}}\right)-\frac{2}{3} \mu_{t} \frac{\partial u_{k}}{\partial x_{k}} \delta_{i j}-\frac{2}{3} \bar{\rho} k \delta_{i j} \\
& \frac{\partial}{\partial t}(\bar{\rho} H-\bar{p})+\frac{\partial}{\partial x_{j}}\left(\bar{\rho} u_{j} H\right)=\frac{\partial}{\partial x_{j}}\left[\left(\frac{\mu}{P r}+\frac{\mu_{t}}{P r_{t}}\right) \frac{\partial h}{\partial x_{j}}\right]+\frac{\partial}{\partial x_{j}}\left(\rho \sum_{k=1}^{N S} h_{k} D_{k} \frac{\partial Y_{k}}{\partial x_{j}}\right) \\
& +\frac{\partial}{\partial x_{j}}\left[u_{j}\left(\mu+\mu_{t}\right)\left(\frac{\partial u_{i}}{\partial x_{j}}+\frac{\partial u_{j}}{\partial x_{i}}-\frac{2}{3} \frac{\partial u_{k}}{\partial x_{k}} \delta_{i j}\right)\right]+\frac{\partial}{\partial x_{j}}\left[\left(\mu+\frac{\mu_{t}}{\sigma_{k}}\right) \frac{\partial k}{\partial x_{j}}\right] \\
& \frac{\partial \bar{\rho} Y_{k}}{\partial t}+\frac{\partial \bar{\rho} u_{j} Y_{k}}{\partial x_{j}}=\frac{\partial}{\partial x_{j}}\left[\left(\frac{\mu}{S c_{k}}+\frac{\mu_{t}}{S c_{t, k}}\right) \frac{\partial Y_{k}}{\partial x_{j}}\right]+\dot{\omega}_{k} \quad \mathrm{k}=1, \mathrm{NS}
\end{aligned}
$$

Menter's Shear Stress Transport model (SST) [11] is used in Loci-STREAM. The SST turbulence model essentially reduces to the $k-\varepsilon$ model near solid walls and transitions to $k-\omega$ model away from the walls with the help of a blending function.

\section{B. Detached Eddy Simulation (DES)}

Detached-Eddy Simulation (DES) was first proposed in 1997 (Spalart et al. [12]). Since then been it has used for many turbulent flow applications and undergone several modifications (Strelets [13], Menter and Kuntz [14], Spalart et al. [15], Shur et al. [16], Spalart [17]). DES is defined by it originators as "a three-dimensional unsteady solution using a single turbulence model, which functions as a sub-grid-scale model in regions where the grid density is fine enough for a large-eddy simulation, and as a Reynolds-averaged model in regions where it is not" (Travin et al. [18]). So, the "LES mode" is activated where grid spacing in all directions is much smaller than the turbulent boundary layer thickness. DES senses the grid density and adjusts to a lower level of eddy viscosity (relative to RANS), thus allowing large-scale instabilities in the flow to occur. In other regions (essentially boundary layers) DES is in the RANS mode though the solution is unsteady in these regions also. Thus, there is a smooth transition between the different regions being modeled. DES was originally developed using the Spalart-Allmaras model as the underlying turbulence model (Spalart et al. [12]) but has since then been extended to Menter's SST model (Strelets [13], Menter et al. [19]).

The idea of DES is applied to the SST model by switching from the SST-RANS model to an LES model based on the turbulent length scale predicted by the SST model which is given by $l_{k-\omega}=k^{1 / 2} / \beta^{*} \omega$. This length scale is replaced by the DES length scale based on the grid spacing $\Delta$. Thus, the destruction term in the turbulent kinetic energy equation can be written as: 


$$
\beta^{*} k \omega=\frac{k^{3 / 2}}{l_{k-\omega}} \stackrel{\text { replaced by }}{\longrightarrow} \frac{k^{3 / 2}}{\delta}
$$

where

$$
\begin{gathered}
\delta=\min \left(l_{k-\omega}, C_{D E S} \Delta\right) \\
\Delta=\max \left(\Delta_{i}\right)
\end{gathered}
$$

with $C_{D E S}$ equal to 0.78 in the wall region and 0.61 in the outer part of the flow. The implementation of the kinetic energy equation used in the SST model can be easily modified for the DES formulation as follows:

$$
\begin{gathered}
\frac{\partial}{\partial t}(\rho k)+\frac{\partial}{\partial x_{i}}\left(\rho u_{i} k\right)=\frac{\partial}{\partial x_{i}}\left[\left(\mu+\sigma_{k} \mu_{t}\right) \frac{\partial k}{\partial x_{i}}\right]+\tilde{P}_{k}-\rho \beta^{*} k \omega \cdot F_{D E S} \\
F_{D E S}=\max \left(\frac{l_{k-\omega}}{C_{D E S} \Delta}, 1\right) ; \quad l_{k-\omega}=\frac{k^{1 / 2}}{\beta^{*} \omega}
\end{gathered}
$$

A recognized problem with the DES is that there is no mechanism to prevent the DES limiter to become activated in an attached boundary layer. Thus, for fine grids, the transition from RANS mode to DES mode can happen inside the boundary layer. This can happen when the local grid spacing near a boundary is smaller than the boundary layer thickness. This can commonly occur with the use of unstructured grids and can lead to what is known as gridinduced separation (Menter et al. [19], Menter and Kuntz [14]). A solution to this has been provided by Menter et al. (2003) which results in the so-called Delayed Detached-Eddy Simulation (DDES). It involves shielding the boundary layer from the DES limiter, thus avoiding grid-induced separation. The blending functions of the SST model are used to formulate a zonal DES limiter as follows:

$$
F_{D E S} \stackrel{\text { replaced by }}{\longrightarrow} F_{D D E S}=\max \left(\frac{l_{k-\omega}}{C_{D E S} \Delta}\left(1-F_{S S T}\right), 1\right)
$$

with $F_{S S T}=0, F_{1}$ or $F_{2}$. Using a value of 0 yields the original SST-DES model of Strelets [13]. Menter et al. [19] recommend using $F_{2}$ which shields most of the boundary layer.

\section{Combustion Model: Laminar Flamelet Model}

In the laminar flamelet model, a turbulent diffusion flame is considered as an ensemble of laminar flamelets [20-23]. At sufficiently large Damkohler number or sufficiently high activation energy, chemical reactions and heat transfer occur in a thin layer. If the characteristic length scale of this layer is smaller than that of the surrounding turbulence, the turbulent structures cannot penetrate the reaction zone and are unable to destroy the flame structure. The effect of turbulence in this so-called flamelet regime results in a deformation and stretching of the flame sheet. With this notion, a flamelet can be considered as a thin reaction zone surrounded by a molecular transport layer, which, in turn, is embedded within a turbulent flow. The one-dimensional laminar flamelet equations can be derived by introducing a new coordinate system that is locally attached to the surface of stoichiometric mixture. If the direction normal to the flame surface is associated with the mixture fraction, and spatial changes along the other coordinate directions are neglected, the following one-dimensional flamelet equations can be derived for unity-Lewis number flame-regimes:

$$
\begin{gathered}
\rho \frac{\partial \boldsymbol{Y}}{\partial t}-\rho \frac{\chi_{Z}}{2} \frac{\partial^{2} Y}{\partial Z^{2}}=\dot{m} \\
\rho \frac{\partial T}{\partial t}-\rho \frac{\chi_{Z}}{2} \frac{\partial^{2} T}{\partial Z^{2}}-\rho \frac{\chi_{Z}}{2} \frac{1}{C_{p}} \frac{\partial C_{p}}{\partial Z} \frac{\partial T}{\partial Z}=\frac{\dot{Q}_{H}}{C_{p}}
\end{gathered}
$$

and the scalar dissipation rate is defined as

$$
\chi_{Z}=2|\alpha \nabla Z|^{2}
$$

Under the assumption that all species are formed on time scales that are short compared to those associated with hydrodynamic and heatloss effects, the temporal derivatives in Eqs. (11)-(12) are neglected. The resulting steadystate flamelet equations are a more convenient form for practical applications as they are time-independent so that all thermochemical species can then be represented only in terms of the scalar dissipation rate and mixture fraction. For application to LES and RANS, the solution of the flamelet equations is precomputed for a prescribed range of 

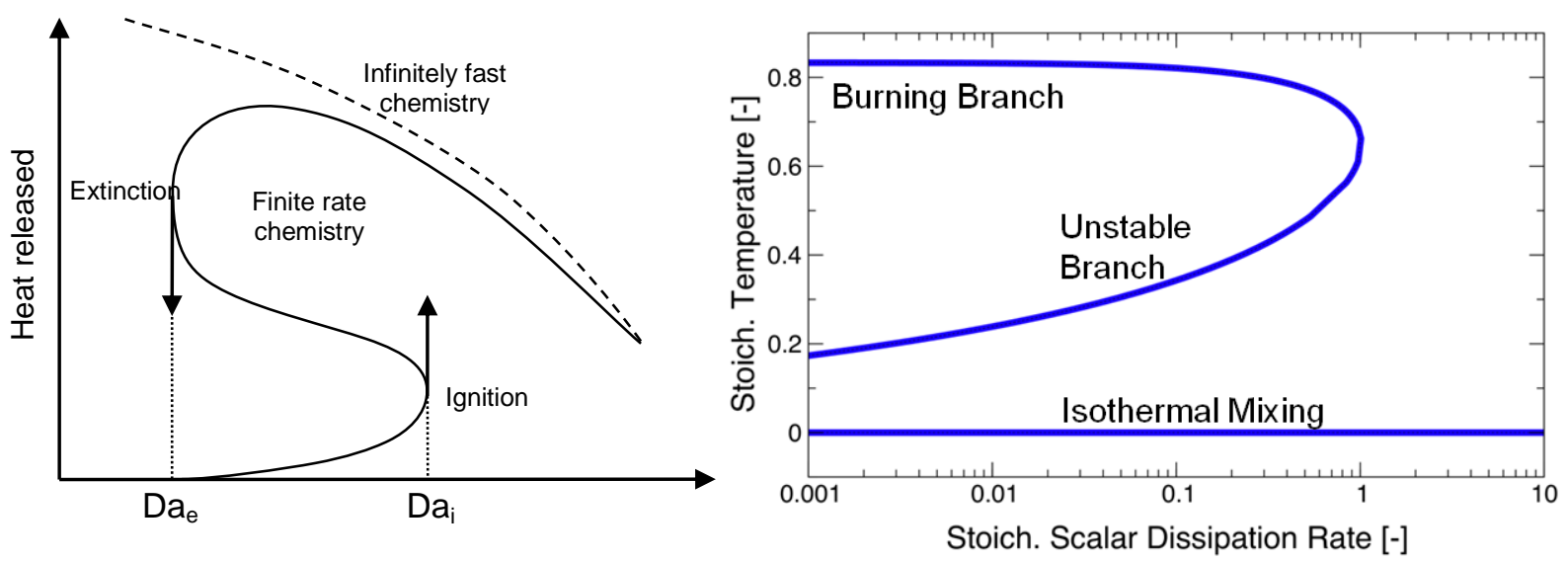

Figure 1. Generic response of the heat released by a 1-dimensional laminar diffusion flame.

scalar dissipation rates and prescribed boundary conditions in the oxidizer $(\mathrm{Z}=0)$ and fuel $(\mathrm{Z}=1)$ streams, respectively.

The solution to the steady flamelet equations is illustrated in Figure 1, showing temperature as function of scalar dissipation rate at stoichiometric condition. In this figure, three distinct branches can be identified, corresponding to the upper stable branch which is associated with the stable burning flame, the middle unstable branch, and the lower branch which corresponds to the mixing between reactants.

\section{Flamelet Model with Wall Heat Transfer}

A limitation of the original flamelet model (described above) is that this model has been derived for adiabatic flames in which heat loss effects, for instance due to radiation and wall heat transfer, are not incorporated. To overcome this limitation, different model extensions have been proposed to account for heat loss effect. These model introduce a defect enthalpy as addition reaction coordinate, and steady laminar flamelets are then generated by reducing the temperature at the boundaries to achieve required enthalpy defects. A major shortcoming of this procedure is that it leads to unrealistic low temperatures at the boundaries for large enthalpy defects. This is remedied by either reducing the solution domain in mixture fraction space [25] or changing the mixture composition at the boundaries[26]. Furthermore, the somewhat arbitrary specification of a uniform enthalpy defect across a laminar flamelet may result in an unphysical description of the corresponding flame structure. In this section, we will present the development of a physics-based model for wall-heat loss effects in the context of the flamelet formulation to accurately characterize convective heat transfer. While effects of thermal radiation have been considered in the flamelet formulation, heat-loss effects by forced convection and conduction are difficult to incorporate. Reason for this is the fact that these heat losses are localized in physical space, and can therefore not directly be represented in the flamelet equations, which are solved in mixture-fraction space. To illustrate this, consider Fig. 2 showing two different scenarios of convective heat-transfer between a diffusion flame (shown by isocontours) and combustor side walls having a constant temperature Twall.

Figure 2(a) illustrates the situation in which the heat flux is primarily aligned with the mixture-fraction gradient. This heat-transfer scenario can be incorporated into the flamelet equations by solving them in the interval $[0 ; \mathrm{Z}(\mathrm{t}$; $\mathrm{xwall})]$ or $[\mathrm{Z}(\mathrm{t}$; xwall; 1$)]$, dependent on whether the fuel-lean or fuel rich-side is aligned with the wall that is here denoted by xwall. Boundary conditions for species composition, temperature, and scalar-dissipation rate are then enforced in the "boundary stream" $\mathrm{Z}(\mathrm{t}$; xwall). However, due to unsteady flame evolution, the location of the wall in mixture-fraction space is a function of time, so that this approach requires a time-dependent flamelet solution. This, in turn, introduces additional challenges for engineering applications for the reason that the flamelet solution is transient and conventional tabulation approaches cannot be employed. Wall-heat transfer perpendicular to the mixture-fraction gradient is shown in Fig. 2(b). Under this condition, the entire flame-structure is affected by heat 


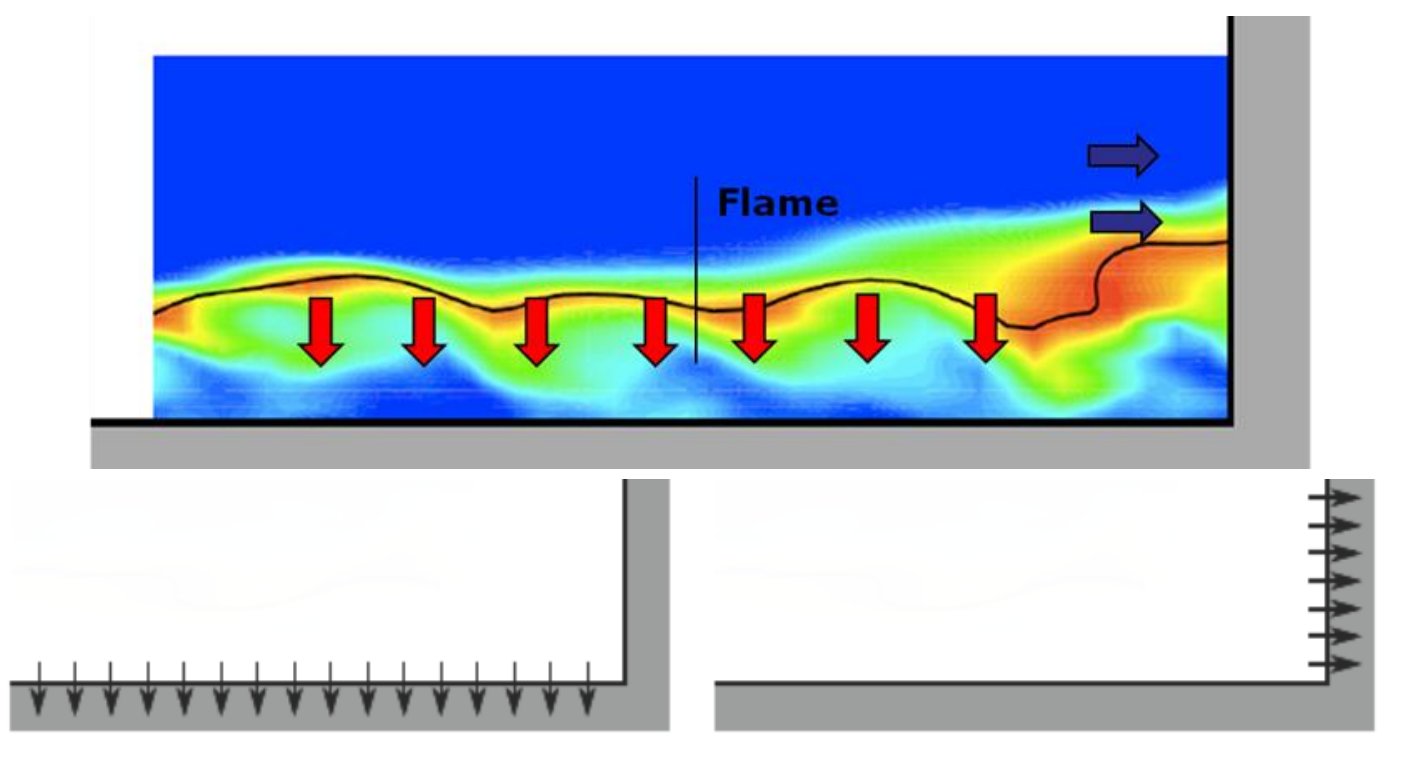

(a) Flame-normal heat transfer

(b) Flame-parallel heat transfer

Figure 2. Schematic of two wall-heat loss scenarios: (a) ame-normal heat transfer, (b) ame-parallel heat transfer.

losses. Since the flamelet-formulation is a one-dimensional representation to a diffusion flame structure, this wallheat transfer scenario cannot be directly represented in terms of a conductive heat flux term.

To represent heat-loss effects in the flamelet formulation, a convective heat-loss term $\dot{Q}_{C}=\dot{Q}_{C}(Z)$ is added to the energy equation. This term acts as heat-sink term over the entire flame-structure, and a proposed model formulation for $\dot{Q}_{C}$ will be discussed next. In the following, heat-loss effects are modeled in terms of forced convective heat transfer. This allows us to develop a model that is consistent with the flamelet/progress variable formulation, and enables the computation and tabulation of the flame-structure prior to the LES/DES calculation. To this end, the following term is added to the right-hand-side of the temperature equation:

$$
\dot{Q}_{C}=\frac{1}{\tau_{C}} \rho\left(T_{\text {wall }}-T\right)
$$

The corresponding non-adiabatic flamelet equations can then be written in the following form:

$$
\begin{gathered}
\rho \frac{\partial Y_{i}}{\partial t}-\rho \frac{\chi_{z}}{2} \frac{\partial^{2} Y_{i}}{\partial Z^{2}}=\dot{\omega}_{i} \\
\rho \frac{\partial T}{\partial t}-\rho \frac{\chi_{z}}{2} \frac{\partial^{2} T}{\partial Z^{2}}-\rho \frac{\chi_{z}}{2 c_{p}} \frac{\partial c_{p}}{\partial Z} \frac{\partial T}{\partial Z}=\frac{\dot{Q}_{H}}{c_{p}}+\underbrace{\frac{1}{\tau_{C}} \rho\left(T_{\text {wall }}-T\right)}_{\text {convective heat loss }}
\end{gathered}
$$

The convective time-scale $\tau_{C}$ can be expressed in terms of heat transfer coefficient $h$, specific heat, density, and a length-scale L:

$$
\tau_{C}=\frac{C_{p} \rho}{h} L
$$

The heat transfer coefficient $h$ can be related to the heat conductivity via the Nusselt number,

$$
N u=\frac{D_{r e f} h}{\lambda}
$$

which compares convective and conductive heat transfer rates. Thus, $\tau_{C}$ is related to the heat conductivity via a Nusselt number relation:

$$
\tau_{C}=\frac{1}{N u} \frac{c_{p} \rho}{\lambda} \frac{\Delta}{D_{r e f}}
$$


Although Nusselt-number relations for reacting flows are not reported, in the following we assume that the flow in the near-wall region of the rocket chamber is fully-developed and turbulent. With this assumption, we approximate the Nusselt number by the following correction[27]:

$$
N u=\frac{\xi \operatorname{Re} \operatorname{Pr}}{k+12.7 \sqrt{\xi}\left(\operatorname{Pr}^{2 / 3}-1\right)}
$$

which has been established for fully-developed turbulent ows in cylindrical pipes. The parameters $\xi$ and $k$ in Eq. (20) are functions of Reynolds and Prandtl numbers, and are given as

$$
\begin{gathered}
k=1.07+\frac{900}{\operatorname{Re}}-\frac{0.63}{1+10 \operatorname{Pr}} \\
\xi=\frac{1}{8}\left[1.82 \log _{10}(\operatorname{Re})-1.64\right]^{-2}
\end{gathered}
$$

The Nusselt-number relation (20) is illustrated in Fig. 3 as function of Reynolds-number for different values of Pr. In this context it is pointed out that the herein proposed non-adiabatic flamelet model is not sensitive to the Nusseltnumber relation. This is due to the fact that the convective heat loss is a slow process and evolves on a long timescale compared to the characteristic chemical time-scale, $\tau_{\text {chem }}$. This can be illustrated by the ratio

$$
\frac{\tau_{C}}{\tau_{\text {chem }}}=\frac{\tau_{C}}{\tau_{\text {flow }}} \cdot \frac{\tau_{\text {flow }}}{\tau_{\text {chem }}}=\frac{1}{C} D a
$$

with $\mathrm{C}=\mathrm{Nu} / \mathrm{Pr}$.Re and $\mathrm{Da}$ is the Damkohler number. This relation shows that for large-Damkohler number diffusion controlled flames the convective time-scale is several order of magnitude smaller than the chemical time-scale, so that the flame-structure reaches a steady state and the chemistry is not affected by transient effects. As such, the convective time-scale only controls that heat-loss rate. In the following FPV formulation, the heat-loss rate and time-scale dependency will be expressed in terms of a reaction progress parameter and enforces consistency with the governing equations that are solved in the LES/DES model.

Effects of wall heat losses on the flamelet solution are illustrated in Fig. 4 showing a comparison between the adiabatic S-shaped curve (red) and the solution of the steady flamelet equations under consideration of convective heat losses (blue dashed line). The fuel/air composition is identical to that specified in the previous section, and the wall temperature is Twall $=500 \mathrm{~K}$. From this figure, it can be seen that heat losses mainly affect the flame structure at low scalar dissipation rates and become increasingly insignificant for larger dissipation rates. Note also that heat losses result in a decrease of the quenching dissipation rate $\chi_{s t, q}$. Flamelets that are obtained from the solution of the unsteady flamelet equations are shown by black symbols. These unsteady flamelet calculations are initialized with the steady-state adiabatic flamelet solutions and integrated for a fixed scalar dissipation rate until the steady

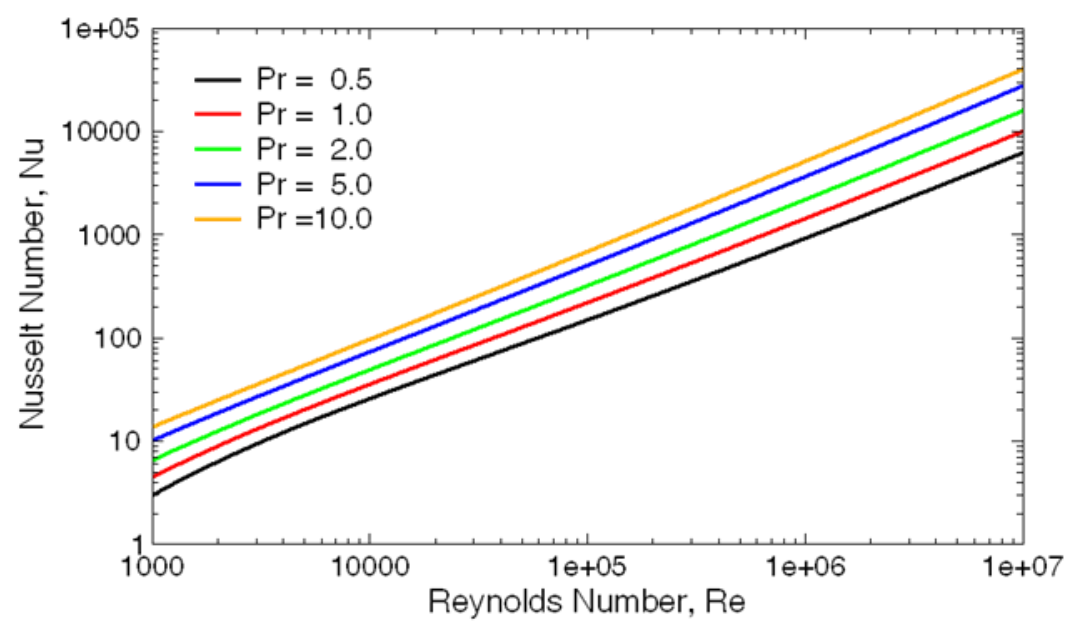

Figure 3. Nusselt-number, evaluated from Eq.(20) as function of Reynolds-number and different values of Prandtl-number. 


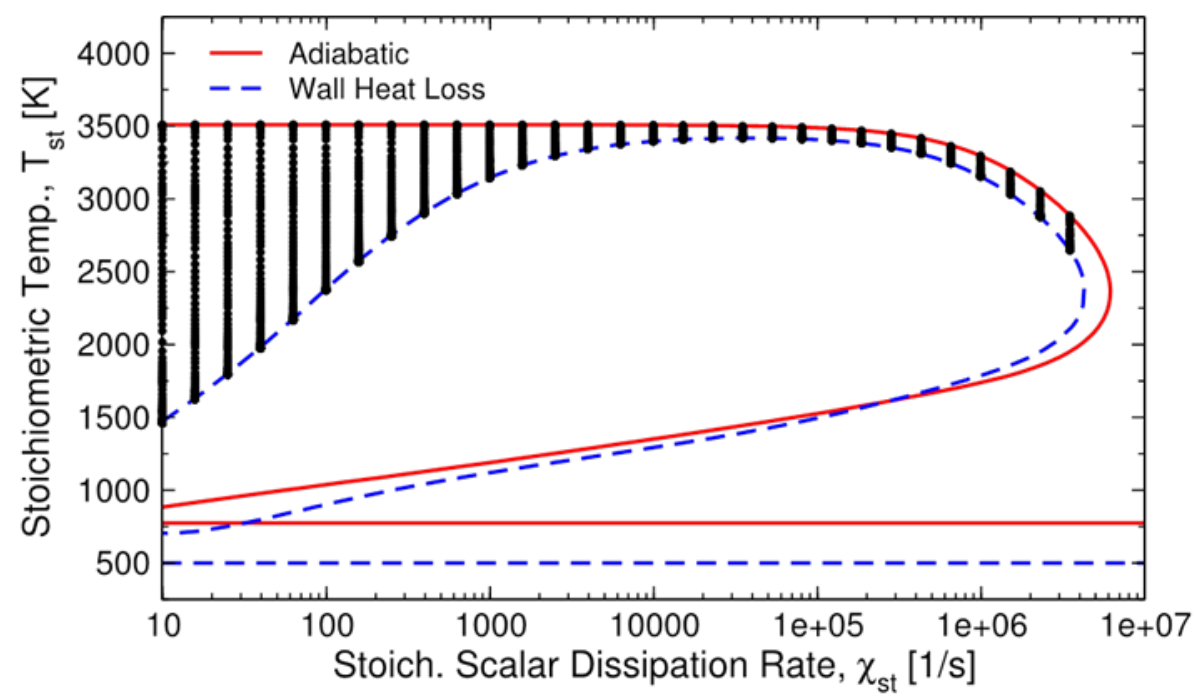

Figure 4. Solution of the steady amelet equations showing temperature as function of scalar dissipation rate at stoichiometric condition for a $\mathrm{H2} / \mathrm{H} 2 \mathrm{O} / \mathrm{O} 2$ ame; red line shows adiabatic steadystate solution; blue dashed line corresponds to the steady-state amelet-solution under consideration of wall-heat losses, and black symbols denote unsteady flamelet-solutions.

non-adiabatic flame-state is reached.

In the following, the transient flamelet solution (shown by the black symbols in Fig 4) is parameterized in terms of mixture fraction, temperature, and stoichiometric scalar dissipation rate, viz.,

$$
\phi=\phi\left(Z, T, \chi_{Z, s t}\right)
$$

where

$$
\begin{gathered}
\phi=\left(Y, \dot{m}, \dot{Q}_{H}, \rho, v, \alpha, C_{p}\right)^{T} \\
\chi_{Z, s t}=\chi_{Z} F(Z)^{-1} \\
F(Z)=\exp \left\{2\left[\operatorname{erfc}^{-1}\left(2 Z_{s t}\right)\right]^{2}-\left[\operatorname{erfc}^{-1}(2 Z)\right]^{2}\right\}
\end{gathered}
$$

In this context it is noted that the total enthalpy is commonly used for the parameterization of non-adiabatic systems for the reason that the solution of the transport equation for the enthalpy is more tractable. However, for the case of flame-quenching and variations in the temperature boundary conditions, the enthalpy is a non-monotonic function. This is illustrated in Fig. 5, showing (a) the temporal evolution of the total enthalpy and (b) the corresponding flamelet temperature for a fixed scalar dissipation rate of $\chi_{z, s t}=0.1 s^{-1}$. This figure shows that the temperature is monotonic, and is therefore used for the parameterization of the flamelet solutions.

To summarize, in the non-adiabatic FPV model presented above temperature is introduced as new coordinate to account for convective and radiative heat-loss effects. To populate this non-adiabatic flamelet state-space, unsteady flamelet computations are performed. The solution of the unsteady flamelet-equations enables the consideration of slow time-scales that are associated with transient heat-loss processes. Unsteady flamelets are then computed for the range of scalar dissipation rates that are accessed during the simulation. This is illustrated in Fig. 4, showing the stoichiometric temperature for a range of scalar dissipation rates, filling out the non-adiabatic flamelet state-space. The thermochemical quantities that are obtained from the solution of the unsteady flamelet equations are then parameterized in terms of moments of mixture fraction and temperature. Using these state variables, all thermochemical quantities are then tabulated in a flamelet library. Turbulence/chemistry interaction is considered through a 
presumed probability density function (PDF) approach, in which a beta-PDF is used for mixture-fraction, and deltafunctions are used for modeling the distribution in temperature.

\section{LES Solver: Methodology}

An LES solver [24] is employed for the first part of this study. In LES, the coherent large scale structures of the turbulent flow are computationally resolved, and effects of the smaller and numerically unresolved scales on the large scales are modeled. The decomposition of the scales is achieved by applying a low-pass filter to the flow field quantities, and - in the case of a reacting flow - the Favre-filtered quantity of a scalar $\psi$ is computed as:

$$
\tilde{\psi}(t, x)=\frac{1}{\rho} \int \rho(t, x) \psi(t, x) G(t, x, y ; \Delta) d y
$$

where $\Delta$ denotes the filter size, which corresponds in the case of an implicit LES to the local LES grid size. The residual field is defined as $\psi^{\prime \prime}(t, x)=\psi(t, x)-\tilde{\psi}(t, x)$ and Favre-filtered quantities are related to Reynolds-filtered quantities by $\bar{\rho} \tilde{\psi}=\overline{\rho \psi}$.

After applying the filter operator to Eqs. (28), the Favre-filtered equations can be written as

$$
\begin{gathered}
\tilde{D}_{t} \bar{\rho}=-\bar{\rho} \nabla \cdot \tilde{u} \\
\bar{\rho} \tilde{D}_{t} \tilde{u}=-\nabla p+\frac{1}{\operatorname{Re}} \nabla \cdot \tilde{\tau}-\nabla \cdot \tau^{\text {res }} \\
\tilde{D_{t}} \tilde{Z}=\frac{1}{\operatorname{Re} S c} \nabla \cdot(\bar{\rho} \tilde{\alpha} \nabla \tilde{Z})-\nabla \cdot \tau_{Z}^{r e s} \\
\bar{\rho} \tilde{D}_{t} \tilde{T}=\frac{1}{\operatorname{Re} S c} \nabla \cdot(\bar{\rho} \tilde{\alpha} \nabla \tilde{T})-\nabla \cdot \tau_{T}^{r e s}+\frac{\dot{Q}_{H}}{C_{p}}+\frac{1}{\operatorname{Re} S c} \bar{\rho} \tilde{\alpha}\left[\partial_{Z} \ln \left(C_{p}\right)+\sum_{i} \tilde{C}_{p, i} \partial_{Z} Y_{i}\right] \nabla \tilde{Z} . \nabla \tilde{T}
\end{gathered}
$$

The residual stress tensor $\stackrel{\tau}{=}^{r e s}=\bar{\rho} u u-\bar{\rho} \tilde{u} \tilde{u}$ and turbulent fluxes $\tau_{\psi}^{r e s}=\bar{\rho} u \psi-\bar{\rho} \tilde{u} \tilde{\psi}$ are modeled by a dynamic Smagorinsky model. The term in square brackets in Eq. (32) has been derived by expanding the thermochemical quantities and species mass fractions to first-order in terms of mixture fraction, neglecting variations in temperature and scalar-dissipation rate. Analysis in the context of a laminar diffusion flame demonstrated the accuracy of this approximation.

The state relation is expressed in terms of Favre-averaged quantities by employing a presumed PDF-closure. To this end, it is integrated over a presumed joint probability density function (PDF) for mixture fraction, temperature, and stoichiometric scalar dissipation rate:

$$
\tilde{\phi}=\iiint \phi\left(Z, T, \chi_{Z, s t}\right) \tilde{P}\left(Z, T, \chi_{Z, s t}\right) d Z d T d \chi_{Z, s t}
$$

and $\tilde{P}\left(Z, T, \chi_{Z, s t}\right)$ denotes the density-weighted joint PDF with

$$
\tilde{P}\left(Z, T, \chi_{Z, s t}\right)=\frac{\rho}{\bar{\rho}} P\left(Z, T, \chi_{Z, s t}\right)=\tilde{P}\left(Z, \chi_{Z, s t}\right) \tilde{P}\left(T \mid Z, \chi_{Z, s t}\right)
$$

In the following, this PDF is modeled as:

$$
\tilde{P}\left(Z, T, \chi_{Z, s t}\right)=\beta\left(Z ; \tilde{Z}, Z^{\prime \prime 2}\right) \cdot \delta(\tilde{T}-T \mid Z) \cdot \delta\left(\chi_{Z, s t}-\chi_{Z, s t}\right)
$$

where a beta-PDF is used to model the mixture fraction distribution, and the distributions of $\chi_{z, s t}$ and $T$ are modeled by a delta function. After computing the Favre-averaged thermochemical quantities, the flamelet library (described below) which is used for the LES-calculations can then be parameterized in terms of the mean and variance of mixture fraction, mean temperature, and mean stoichiometric scalar-dissipation rate, respectively. This expression can be written in the following form:

$$
\tilde{\phi}=\tilde{\phi}\left(\tilde{Z}, Z^{\prime \prime 2}, \tilde{T}, \chi_{Z, s t}\right)
$$




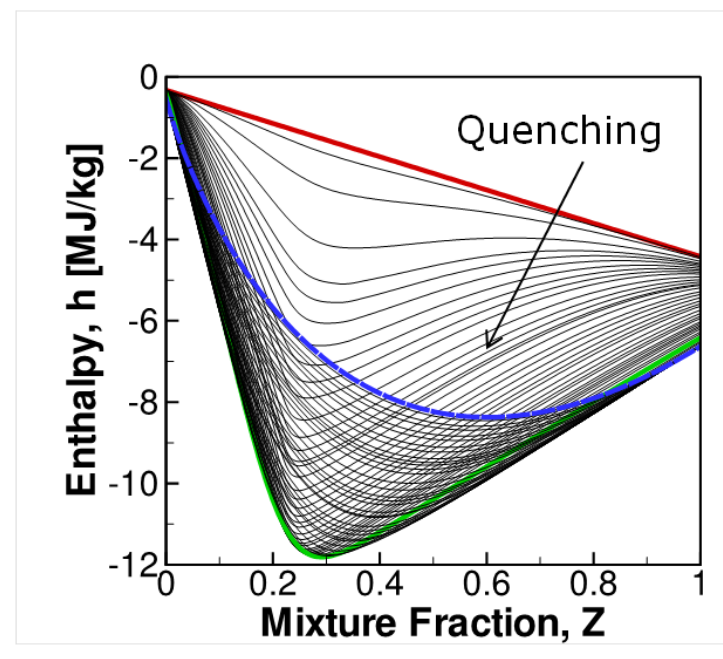

(a) Evolution of total enthalpy

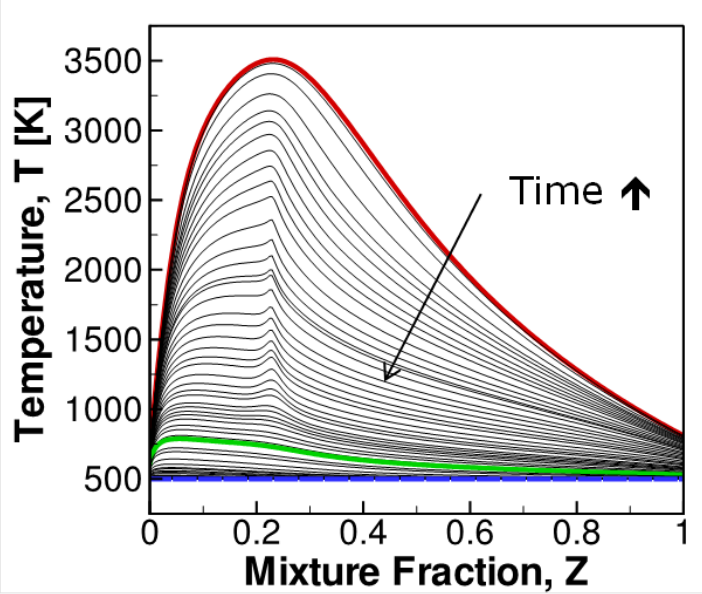

(b) Evolution of temperature

Figure 5. Evolution of (a) total enthalpy (consisting of chemical and sensible contributions) and (b) temperature for a constant scalar dissipation rate of_Z;st $=0: 1 \mathrm{~s} \square 1$. The red line correspond to the adiabatic solution and the blue dashed line denotes the steady solution for the case with wall-heat losses.

\section{Coupling of Loci-STREAM (URANS/DES solver) with Flamelet Model}

As mentioned earlier, for the non-adiabatic flamelet model, temperature is used for the parameterization of the flamelet solutions, i.e., the energy equation is cast with temperature, instead of enthalpy (or stagnation enthalpy) as the dependent variable. The Favre-averaged temperature equation can be written as:

$$
\frac{\partial}{\partial t}(\bar{\rho} \tilde{T})+\nabla \cdot(\bar{\rho} u T)=\frac{1}{\tilde{c}_{p}} \nabla \cdot(\lambda \nabla T)+\bar{\rho} \tilde{\alpha}(\underbrace{\left(\sum_{i} \frac{c_{p, i}}{c_{p}} \frac{\partial Y_{i}}{\partial Z}\right)}_{B} \nabla Z \cdot \nabla T+\bar{\rho} \underbrace{\left(\frac{\dot{q}_{H}}{\rho c_{p}}\right)}_{C}+\nabla \cdot\left(\bar{\rho} \tilde{u} \tilde{T}-\bar{\rho} u^{\prime \prime} T^{\prime \prime}\right)
$$

The Favre-averaged momentum and continuity equations remain unchanged. Incorporating the turbulence modeling assumptions, the equations for the mean mixture fraction, variance of mixture fraction, and temperature can be written as:

$$
\begin{aligned}
& \frac{\partial \bar{\rho} Z}{\partial t}+\frac{\partial \bar{\rho} u_{j} Z}{\partial x_{j}}=\frac{\partial}{\partial x_{j}}\left[\left(\bar{\rho} D+\frac{\mu_{t}}{S c_{t}}\right) \frac{\partial Z}{\partial x_{j}}\right] \\
& \frac{\partial \bar{\rho} Z^{\prime \prime 2}}{\partial t}+\frac{\partial \bar{\rho} u_{j} Z^{\prime \prime 2}}{\partial x_{j}}=\frac{\partial}{\partial x_{j}}\left(\frac{\mu_{t}}{S c_{t}} \frac{\partial Z^{\prime \prime 2}}{\partial x_{j}}\right)+2 \frac{\mu_{t}}{S c_{t}} \frac{\partial Z}{\partial x_{j}} \frac{\partial Z}{\partial x_{j}}-\bar{\rho} \chi \\
& \frac{\partial}{\partial t}(\bar{\rho} \tilde{T})+\nabla \cdot(\bar{\rho} \boldsymbol{u} T)=\frac{1}{\tilde{c}_{p}} \nabla \cdot\left[\left(\lambda+\frac{c_{p} \mu_{t}}{\operatorname{Pr}_{T}}\right) \nabla T\right]+\underset{A}{\bar{\alpha} \tilde{\alpha}} \underbrace{\left(\sum_{i} \frac{c_{p, i}}{c_{p}} \frac{\partial Y_{i}}{\partial Z}\right)}_{B} \nabla Z \cdot \nabla T+\bar{\rho} \underbrace{\left(\frac{\dot{q}_{H}}{\rho c_{p}}\right)}_{C}+\frac{1}{\tilde{c}_{p}}\left(\frac{D p}{D t}+\tau: \boldsymbol{u}\right)
\end{aligned}
$$

The temperature equation is derived by using the following expansion:

$$
\nabla Y_{i}=\nabla Z \frac{\partial Y_{i}}{\partial Z}+\nabla T \frac{\partial Y_{i}}{\partial T}+\nabla \chi_{s t} \frac{\partial Y_{i}}{\partial \chi_{s t}}
$$




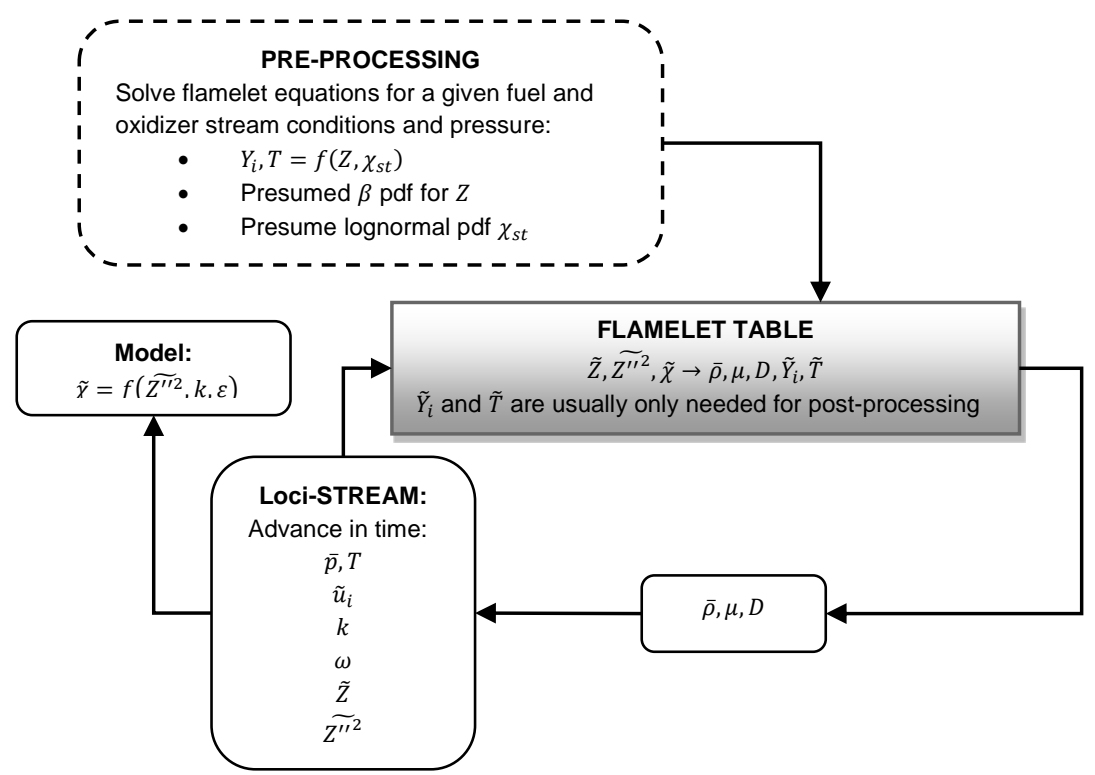

Figure 6. Flow chart for coupling laminar flamelet model with Loci-STREAM.

and simplifying by omitting the last two expansion terms. A physical rationale for this approximation is that changes of a thermochemical quantity with respect to $T$ or $\chi_{s t}$ are small compared to changes with respect to mixture fraction.

The terms A, B, and C along with $\bar{\rho}, \tilde{\lambda}$ and $\tilde{c}_{p}$ appearing in Eq. (40) are tabulated in the flamelet table. The flamelet library is tabulated in terms of $\tilde{Z}, Z^{\prime \prime 2}$ and the stoichiometric scalar dissipation rate, $\chi_{s t}$. To evaluate $\chi_{s t}$ from the, we use the relation:

$$
\chi(Z)=\chi_{s t} F(Z)
$$

or in terms of Favre-averaged quantities:

$$
\chi(Z)=\chi_{s t} F\left(Z, Z^{\prime \prime 2}\right)
$$

By inverting this equation, we can evaluate $\chi_{s t}$ as

$$
\chi_{s t}=\frac{\chi(Z)}{F\left(Z, Z^{\prime \prime 2}\right)}
$$

The term $F\left(Z, Z^{\prime \prime 2}\right)$ is tabulated in the chemistry library. Note that $F\left(Z, Z^{\prime 2}\right) \rightarrow 0$ for $Z=\{0,1\}$. To ensure that the denominator in Eq. (44) remains bounded, $F$ is clipped as $F=\max (\varepsilon, F)$ where $\varepsilon$ is a small value $\left(\varepsilon \sim 10^{-5}\right)$.

The mean scalar dissipation rate is obtained from an algebraic model:

$$
\chi(Z)=c_{\chi} c_{\mu} \omega Z^{\prime \prime 2}, \quad \text { where } c_{\chi}=2, c_{\mu}=0.09
$$

Finally, the flamelet library is tabulated in terms of $\tilde{Z}, Z^{\prime \prime 2}, T$ and $\log _{10}\left(\chi_{s t}\right)$ which can be represented as:

$$
\tilde{Z}, Z^{\prime \prime 2}, \tilde{T}, \log _{10}\left(\chi_{s t}\right) \stackrel{\text { Table lookup }}{\longrightarrow} \bar{\rho}, \tilde{\mu}, \tilde{\lambda}, c_{p}, \tilde{F}, A, B, C
$$

The coupling of the flamelet model with the flow solver, Loci-STREAM [7], is illustrated in Figure 6.

\section{Results}

In this work, the single-unit rocket injector experiment by Pal et al. was considered [28]. A schematic of their experimental setup is shown in Figure 7. The main chamber wall is instrumented with coaxial heat flux gauges which provide both temperature and heat flux profiles. In this facility, the gaseous hydrogen (GH2) and gaseous 


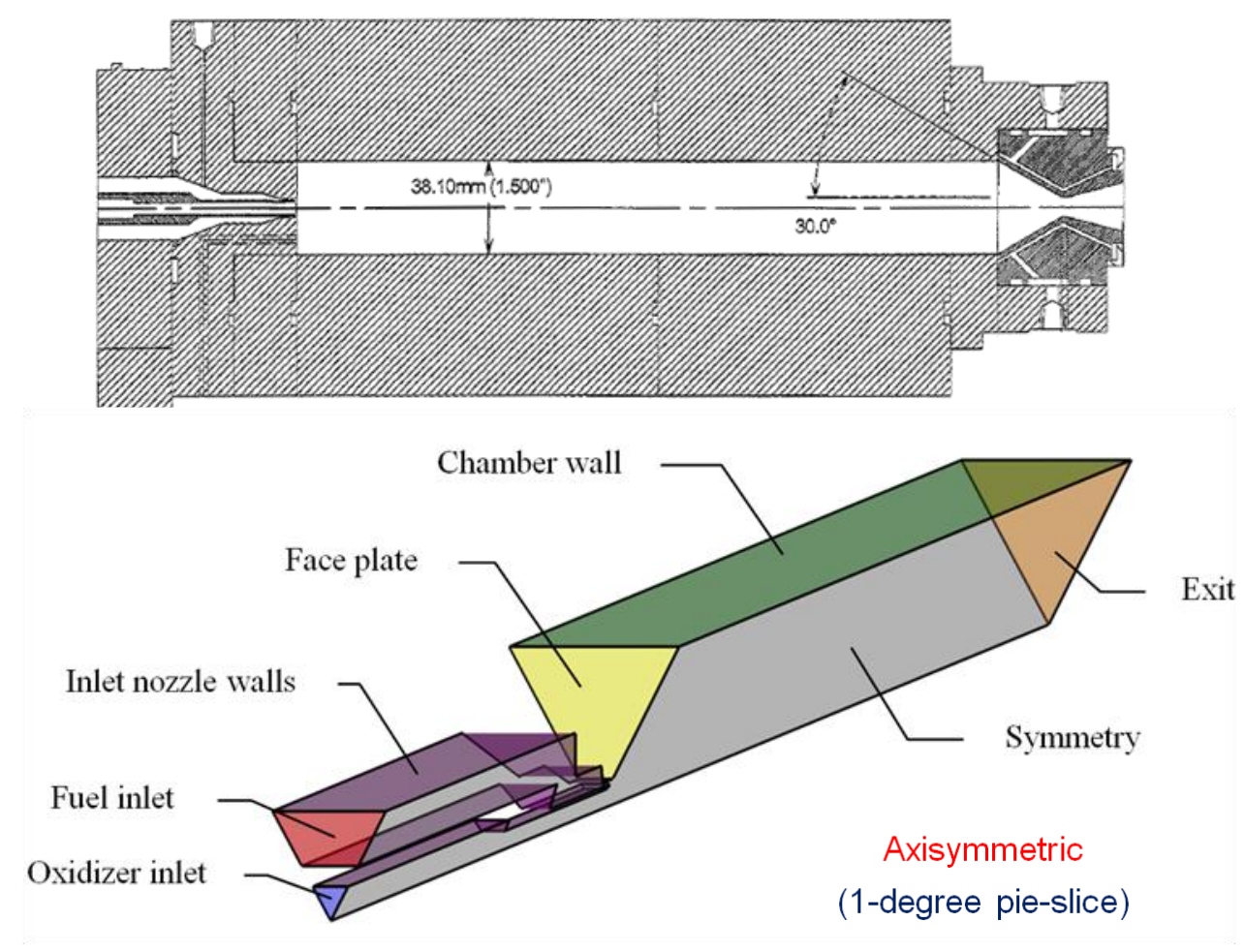

Figure 7. (Top) Schematic of the experiment ${ }^{40}$ and (Bottom) schematic of the computational domain used for the simulations.

oxygen (GO2) are supplied through a coaxial injector into the combustion chamber. The rocket chamber provides optical access for laser diagnostics measurements. The mass flow rates for the gaseous oxygen, hydrogen, and nitrogen are $10.3 \mathrm{~g} / \mathrm{s}, 42 \mathrm{~g} / \mathrm{s}$, and $10 \mathrm{~g} / \mathrm{s}$, respectively, and the chamber pressure is 12.9 bar. The GO2 post of the injector had an inner diameter of $7.75 \mathrm{~mm}$ and was not recessed with respect to the injector face. The inner and outer diameters of the fuel annulus were $9.53 \mathrm{~mm}$ and $12.7 \mathrm{~mm}$, respectively. Point-wise measurements of velocity, and mole fractions of $\mathrm{H} 2$ and $\mathrm{O} 2$ were performed, and these data are used for model validation. For computational simulations, the detailed $\mathrm{H} 2 / \mathrm{O} 2$ mechanism by O'Conair et al. [29] was used. Individual flamelets for different scalar dissipation rates were computed, and temperature, species mass fraction, density, and other thermoviscous properties were tabulated in terms of mean and variance of mixture fraction, and mean progress variable.

Computational domain and boundary condition types for the injector geometry are shown in Figure 7. Axisymmetric domain is modeled with a 1-degree pie-shaped grid (circumferential dimension is exaggerated in Figure 7 for clarity). For the finite rate chemistry model simulation, for the chamber wall thermal boundary condition, options of assigning a uniform temperature $(700 \mathrm{~K})$ or prescribing the measured temperature profile are evaluated whereas the face plate and exit nozzle temperatures are set to upstream and downstream ends of the measured wall temperature data, respectively. An extrapolated boundary condition is used at the supersonic exit, so the chamber pressure is not imposed but followed from the solution. 

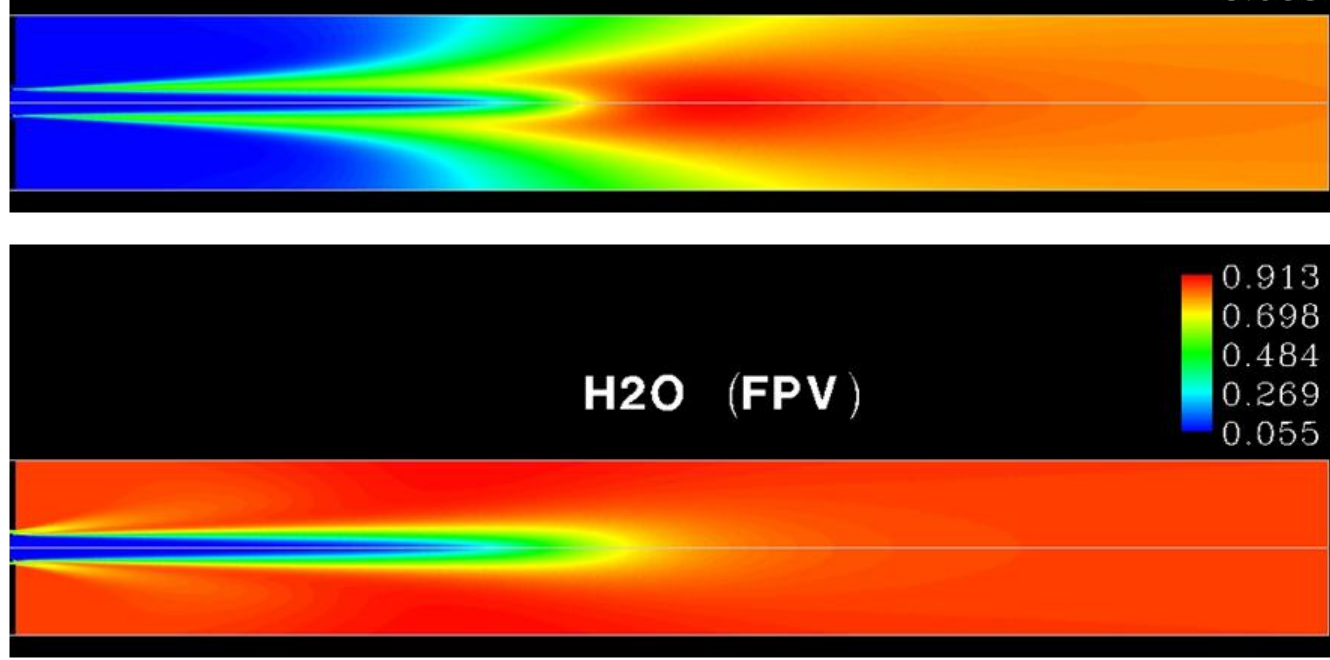

Figure 8. Steady Flamelet-Progress-Variable model results.

Figure 8 shows the temperature and species $(\mathrm{OH}$ and $\mathrm{H} 2 \mathrm{O})$ contours in the injector obtained with the flamelet progress variable (FPV) model. Figure 9 shows the mixture fraction field in the injector. The solid black line on each graph indicates the stoichiometric mixture fraction at $Z=0.229$. Figure 9 shows the contours of mixture fraction variance. To normalize the plot, $\mathrm{x}$ axis has been divided by $\mathrm{D}$, the fuel annulus diameter. The flamelet models yield solutions qualitatively similar to the finite rate chemistry model. The FPV simulations, in comparison to the adiabatic finite rate chemistry (FRC) model simulation, produce a noticeably lower mean temperature field near the flame region. Furthermore, the oxygen core extends further downstream indicating slower mixing and hence a larger flame length. 


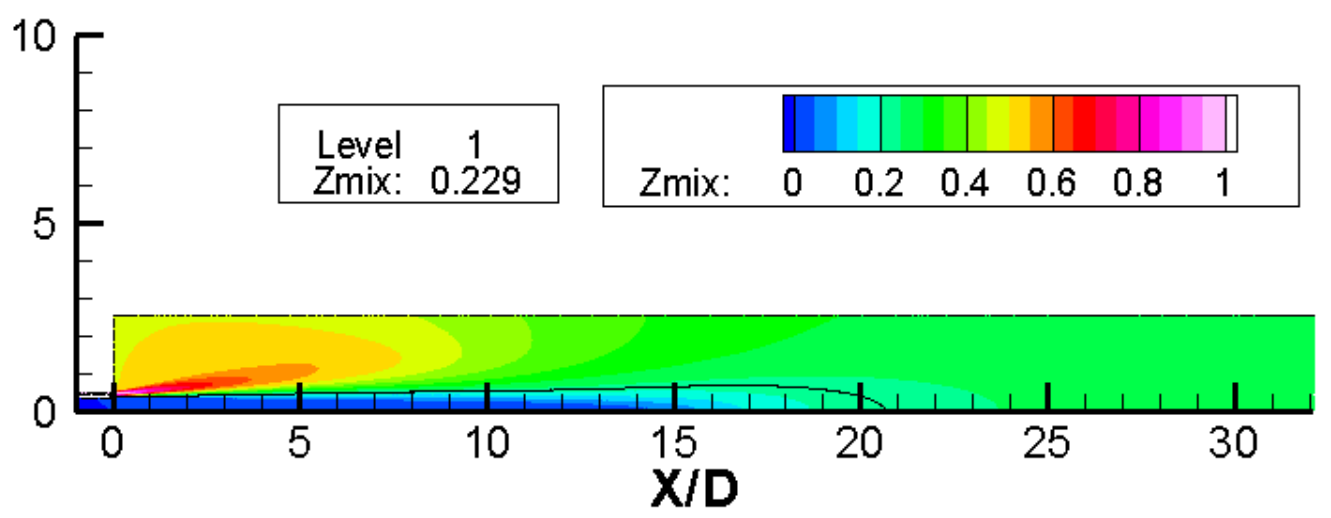

Figure 8. Mixture fraction contours.

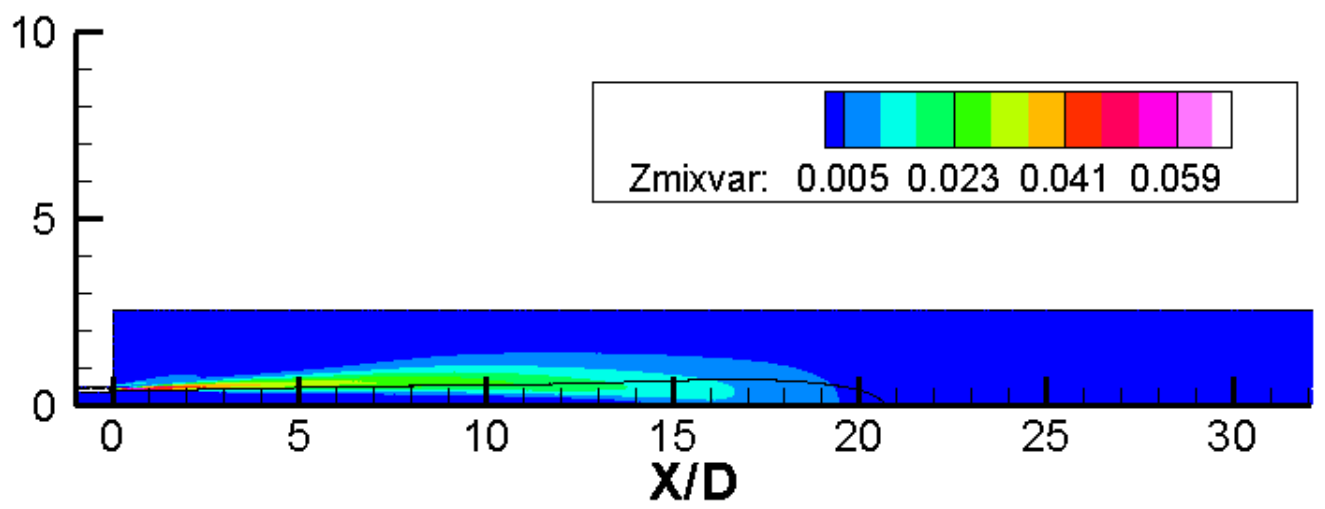

Figure 9. Variance of mixture fraction contours.

The FPV flamelet model has been coupled with the Hybrid RANS-LES (DES) capability in Loci-STREAM. The above GOX-GH2 injector geometry is used to demonstrate this coupling. The FPV-HRLES simulation is started from the steady state FPV-RANS simulation. Temperature contours at four time instants $(0.1 \mathrm{~ms}, 5 \mathrm{~ms}, 10 \mathrm{~ms}$, and $15 \mathrm{~ms}$ ) are shown in Figure 10. The unsteady nature of the flow field is obvious from these plots. The shear layer instabilities occurring in the GOX jet lead to large scale vortices being shed downstream. It can be observed from this HRLES simulation that the hot gases get transferred in the recirculation region (upper left corner of the combustion chamber in Figure 10(d) which is not observed in the steady state RANS simulation shown earlier.

Finally, the non-adiabatic flamelet combustion model was applied in LES to the uni-element rocket injector of Pal et al. [29]. Figure 11 compares mean temperature fields that were obtained with the non-adiabatic flamelet model (top) and the adiabatic flamelet computation (bottom). This comparison shows that heat-loss effects are particularly pronounced in the recirculation region. The long residence time in these recirculation regions promotes the heattransfer from the hot reaction products to the injector side wall, thereby affecting the temperature and radical distribution in the combustor core-region. This is further emphasized by the comparison of radial temperature profiles in Fig. 12. 


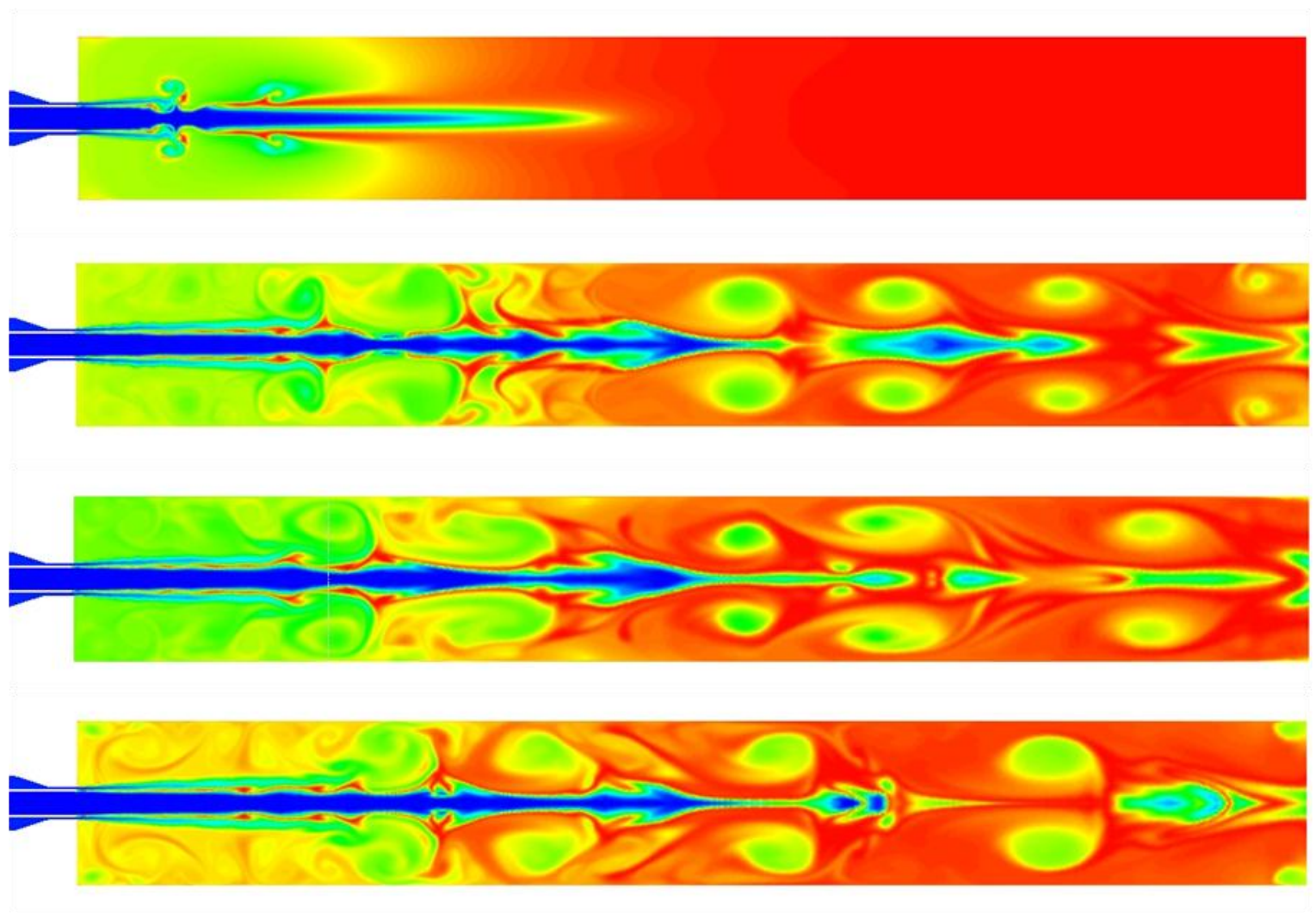

Figure 10. Temperature contours from the FPV-HRLES simulation of the GOX/GH2 uni-element injector. Starting from the steady state simulation, 4 time instants are shown above (top to bottom): (a) $0.1 \mathrm{~ms}$, (b) $5 \mathrm{~ms}$, (c) $10 \mathrm{~ms}$, and (d) $15 \mathrm{~ms}$.

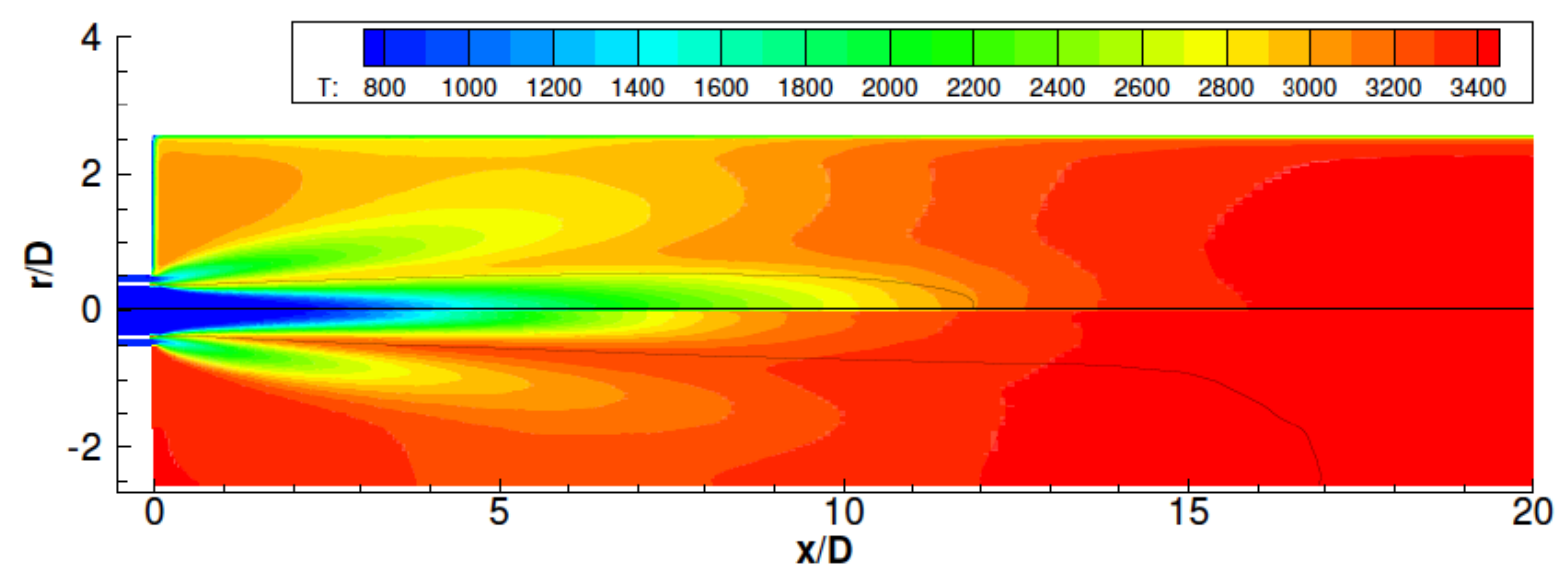

Figure 11: LES computation of uni-element rocket injector: comparison of the mean-temperature field obtained with novel non-adiabatic FPV model (top) and conventional adiabatic formulation (bottom). 

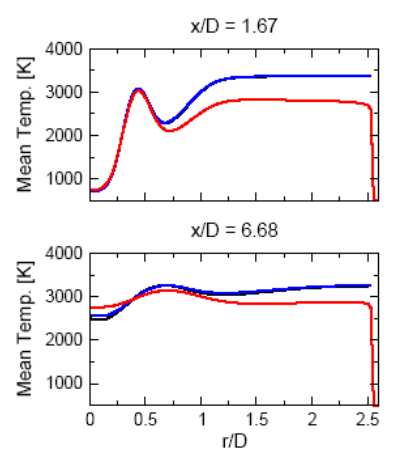

(a) Temperature

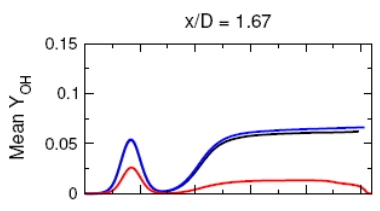

$\mathrm{x} / \mathrm{D}=6.68$

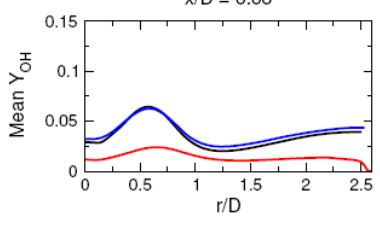

(b) OH mass fraction.
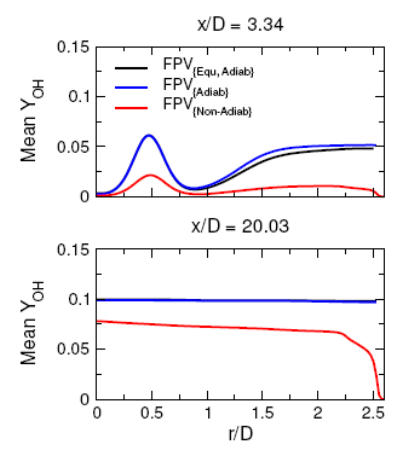

Figure 12: LES computation of uni-element rocket injector: radial profiles of mean temperature and $\mathrm{OH}$ radical at four locations in the combustion chamber.

From this direct comparison several observations can be made. First, the boundary layer is mainly apparent in the recirculation region and the combustor end wall. The boundary layer increases with increasing down-stream distance, which is also evident from the radial profiles presented in Figure 12. Second, considerable effects of the wall-heat loss on the flame/flow-field structure can be observed in the region up to eight diameters downstream of the combustor end wall. In this region the flame temperature decreases by as much as $500 \mathrm{~K}$ throughout the combustion chamber. With increasing downstream distance the temperature inside the combustor core region equilibrates, and heat-loss effects become increasingly confined to the combustor-wall.

The hydroxyl-radical mass fraction also shows a pronounced sensitivity to the temperature field. Specifically, it can be seen from Figure 12(b) that for $\mathrm{x} / \mathrm{D}<1$ the mean $\mathrm{OH}$-mass fraction is almost completely diminished outside the flame zone, and composition at the exit of the rocket-computer is reduced by approximately 25 percent compared to the adiabatic predictions. Overall, considerable differences can be observer for the LES-computations in which heatloss effects are considered. These effects are most prominent in the recirculation region where the residence times are large. Although the boundary layer is not fully resolved and radiative heat losses have not been incorporated in this calculation, it is anticipated that the consideration of these effects will result in further increase in heat-losses and increased variation in the combustor flow field.

A major limitation of the experimental database [28] is that only data for wall heat-transfer have been reported, and no measurements of velocity, temperature and speciation in the combustion chamber are available. As such, this incomplete database only offers limited capability for a comprehensive validation of the combustion model. In order to assess the accuracy of the non-adiabatic FPV model, we are in the process of conducting a direct numerical simulation of a planar wall jet that is operated at conditions that are relevant to rocket-combustion. The particular advantage of this approach is that this database will provide access to all space-time resolved flow-field quantities, and therefore will enable a comprehensive analysis of all underlying modeling assumptions of this combustion model. The ongoing research involves two steps:

\section{Summary}

The application of a novel wall heat transfer model in the laminar flamelet framework is presented in this paper. The model is coupled to an LES flow solver and a URANS/DES solver called Loci-STREAM. The overall methodology has been found to be quite robust. The application used to test this model is a uni-element shear coaxial GO2-GH2 injector. The investigation of this particular application is still ongoing and the results presented here are preliminary. Further validation of this non-adiabatic flamelet model is under way.

\section{Acknowledgments}

This work has been partially supported by STTR project NNX11CC73C funded by NASA Marshall Space Flight Center. The authors gratefully acknowledge the technical discussions with Kevin Tucker and Jeff West of NASA Marshall Space Flight Center. 


\section{References}

${ }^{1}$ M. J. Foust, M. Deshpande, S. Pal, T. Ni, C. L. Merkle, and R. J. Santoro. Experimental and analytical characterization of a shear coaxial combusting GO2/GH2 flowfield. AIAA Paper 96-0646 (1996).

${ }^{2}$ M. J. Foust, S. Pal, and R. J. Santoro. Gaseous propellant rocket studies using raman spectroscopy. AIAA Paper 96-2766 (1996).

${ }^{3}$ C. D. Pierce and P. Moin. Progress-variable approach for large-eddy simulation of non-premixed turbulent combustion. J. Fluid Mech., 504:73-97, (2004).

${ }^{4}$ M. Ihme, C. M. Cha, and H. Pitsch. Prediction of local extinction and re-ignition effects in nonpremixed turbulent combustion using a flamelet/progress variable approach. Proc. Combust. Inst., 30:793-800 (2005).

${ }^{5}$ P. K. Tucker, S. Menon, C. L. Merkle, J. C. Oefelein, and V. Yang. Validation of high-fidelity CFD simulations for rocket injector design. AIAA Paper 2008-5226, (2008).

${ }^{6}$ S. Pal, W. Marshall, R. Woodward, and R. Santoro. Wall heat flux measurements for a uni-element go2/gh2 shear coaxial injector, 2006. Third International Workshop on Rocket Combustion Modeling, Paris, France, March, 13-15 (2006).

${ }^{7}$ Thakur, S., Wright, J. and Shyy, W., “An Algorithm for Chemically Reacting Flows on Generalized Grids Using a Rule-Based Framework," 43 $3^{\text {rd }}$ AIAA Conference, Paper No. 2005-0875, Reno, NV (Jan 2005).

${ }^{8}$ Patankar, S. V., Numerical Heat Transfer and Fluid Flow, Hemisphere, Washington, DC (1980).

${ }^{9}$ Rhie, C.L. and Chow, W.L., "A Numerical Study of the Turbulent Flow Past an Isolated Airfoil with Trailing Edge Separation," AIAA Journal, 21: 1525-1532 (1983).

10 Luke, E.A., "LOCI: A Deductive Framework for Graph-Based Algorithms," Third International Symposium on Computing in Object-Oriented Parallel Environments, edited by S. Matsuoka, R. Oldehoeft and M. Tholburn, No. 1732 in Lecture Notes in Computer Science, Springer-Verlag, pp 142-153 (1999).

11 Menter, F.R., "Two-Equation Eddy-Viscosity Turbulence Models for Engineering Applications," AIAA J., Vol. 32, No. 8, pp 269-289 (1994).

12 Spalart, P.R., Jou, W.H., Strelets, M. and Allmaras, S.R., "Comments on the Feasibility of LES for Wings and on a Hybrid RNAS/LES Approach," $1^{\text {st }}$ AFOSR Conference on DNS/LES, (1997).

13 Strelets, M., "Detached Eddy Simulation of Massively Separated Flows," AIAA Paper 2001-0879 (2009).

14 Menter, F.R. and Kuntz, M, "Adaptation of Eddy-Viscosity Turbulence Models to Unsteady Separated Flows Behind Vehicles," The Aerodynamics of Heavy Vehicles: Trucks, Buses and Trains, McCallen, R., Browand, F. and Ross, J., eds., Springer, New York (2004).

15 Spalart, P.R., Deck, S., Shur, M.L., Squires, K.D., Strelets, M.K. and Travin, A., “A New Version of Detached-Eddy Simulation, Resistant to Ambiguous Grid Densities," Theor. Cimput. Fluid Dyn., Vol. 20, pp 181-195 (2006).

16 Shur, M.L., Spalart, P.R., Strelets, M.K. and Travin, A.K., "A Hybrid RANS-LES Approach with Delayed-DES and WallModelled LES Capabilities," Int. J. Heat Fluid Flow, Vol. 29, pp 1638-1649 (2008).

17 Spalart, P.R., "Detached-Eddy Simulation,” Ann. Rev. Fluid Mech., Vol. 41, pp 181-202 (2009).

18 Travin, A., Shur, M., Strelets, M. and Spalart, P.R., "Detached-Eddy Simulations Past a Circular Cylinder," Flow Turb. And Comb., Vol. 63, pp 293-313(1999).

19 Menter, F. R., Kuntz, M., and Langtry, R., "Ten Years of Industrial Experience with the SST Turbulence Model," Turbulence, Heat and Mass Transfer 4, ed: K. Hanjalic, Y. Nagano, and M. Tummers, Begell House, Inc., pp. 625 - 632 (2003).

20 Bray, K. N. C. and Peters, N., "Laminar Flamelets in turbulent Flames," Turbulent Reacting Flows, edited by P. A. Libby and F. A. Williams, Academic Press, London, pp. 63-113 (1994).

21 N. Peters. Laminar diffusion flamelet models in non-premixed turbulent combustion. Prog. Energy Combust. Sci., 10(3):319339 (1984).

22 N. Peters. Local quenching due to flame stretch and non-premixed turbulent combustion. Combust. Sci. Tech., 30:1-17 (1983).

23 N. Peters. Turbulent Combustion. Cambridge University Press, Cambridge (2000).

24 M. Ihme and Y. C. See. LES flamelet modeling of a three-stream mild combustor: Analysis of flame sensitivity to scalar inflow conditions. Proc. Combust. Inst., 33, in press (2010).

25 Marracino, B. and Lentini, D., "Radiation Modelling in Non-Luminous Nonpremixed Turbulent Flames," Combust. Sci. Tech., Vol. 128, No. 1-6, 1997, pp. 23-48.

26 Hossain, M., Jones, J. C., and Malalasekera, W., "Modelling of a Bluff-Body Nonpremixed Flame Using a Coupled Radiation/Flamelet combustion model," Flow. Turb. Combust., Vol. 67, No. 3, 2001, pp. 217-234.

27 Gnielinski, V., "Neue Gleichungen fur den Warme- und den Stoffubergang in turbulent durchstromten Rohren und Kanalen," Forsch. Ing.-Wes., Vol. 41, No. 1, 1975, pp. 8-16. 
28 S. Pal, W. Marshall, R. Woodward, and R. Santoro. Wall heat flux measurements for a uni-element GO2/GH2 shear coaxial injector, 2006. Third International Workshop on Rocket Com-bustion Modeling, Paris, France, March, 13-15.

29 M. O'Conaire, H. J. Curran, J. M. Simmie, W. J. Pitz, and C. K. Westbrook. A comprehensive modeling study of hydrogen oxidation. Int. J. Chem. Kinet., 36:603-622 (2004). 